\title{
Association Between Air Conditioning Use and Self-reported Symptoms During the 2018 Heat Wave in Korea
}

\author{
Yong-Han Lee', Sanghyuk Bae'2, Seung-sik Hwang ${ }^{3}$, Jong-Hun Kim ${ }^{4}$, Kyoung-Nam Kim ${ }^{5,6}$, Youn-Hee Lim7, Miji Kim ${ }^{8}$, \\ Sohwa Jung ${ }^{3}$, Ho-Jang Kwon ${ }^{1}$ \\ ${ }^{1}$ Department of Preventive Medicine, Dankook University College of Medicine, Cheonan, Korea; ${ }^{2}$ Department of Preventive Medicine, College of \\ Medicine, The Catholic University of Korea, Seoul, Korea; ${ }^{3}$ Department of Public Health Sciences, Graduate School of Public Health, Seoul National \\ University, Seoul, Korea; ${ }^{4}$ Department of Social and Preventive Medicine, Sungkyunkwan University School of Medicine, Suwon, Korea; ${ }^{5}$ Division of \\ Public Health and Preventive Medicine, Seoul National University Hospital, Seoul, Korea; ${ }^{6}$ Department of Preventive Medicine, Seoul National \\ University College of Medicine, Seoul, Korea; ${ }^{7}$ Institute of Environmental Medicine, Seoul National University of Medical Research Center, Seoul, \\ Korea; ${ }^{8}$ Department of Preventive Medicine, Gyeongsang National University College of Medicine, Jinju, Korea
}

Objectives: The purpose of this study was to investigate the health effects of air conditioning use during the 2018 heat wave in Korea, included the highest temperature ever recorded in the nation.

Methods: The participants in this study were 1000 adults aged 19 years and older recruited from across Korea. The participants were asked about their experience of symptoms of various diseases, disruptions of their daily lives, and use of air conditioning during the heat wave. The associations between air conditioning use during the heat wave and health outcomes were analyzed using the chisquare test and multiple logistic regression models.

Results: Among participants who lacked air conditioning in the main space where they spent time outside the home, 33.9\%, 8.1\%, 43.5\%, and 19.4\% experienced symptoms of heat-related, cardiovascular, nervous system diseases, and air-conditioningitis, respectively. In comparison, participants who did have air conditioning outside the home experienced the same symptoms at proportions of $21.0 \%, 1.9 \%, 26.8 \%$, and $34.2 \%$, respectively ( $p=0.027,0.007,0.007$, and 0.023 , respectively). Among participants who had no air conditioner at home, $10.0 \%$ were absent from school or work due to the heat wave. In contrast, among participants who had an air conditioner at home, only $3.7 \%$ were absent as a result of the heat wave $(p=0.007)$.

Conclusions: When air conditioning was not used at home or in the main space where participants spent time outside the home during the 2018 heat wave, adverse health effects were more prevalent, but the risk of air-conditioningitis was reduced.

Key words: Air conditioning, Health effects, Heat wave, Symptoms, Republic of Korea

Received: June 27, 2019 Accepted: November 26, 2019

Corresponding author: Ho-Jang Kwon, MD, PhD Department of Preventive Medicine, Dankook University College of Medicine, 119 Dandae-ro, Dongnam-gu, Cheonan 31116, Korea E-mail: hojangkwon@gmail.com

This is an Open Access article distributed under the terms of the Creative Commons Attribution Non-Commercial License (https://creativecommons.org/licenses/bync/4.0/) which permits unrestricted non-commercial use, distribution, and reproduction in any medium, provided the original work is properly cited.

\section{INTRODUCTION}

Heat waves typically involve sudden, severe heat above a certain temperature that continues over a period of days. The temperatures and standards used to define a heat wave vary from country to country. The United States defines a heat wave as a period of more than 3 consecutive days of peak daily temperatures exceeding $32.2^{\circ} \mathrm{C}[1]$. Korea has operated a heat wave 
alert system since June 2008. According to Korean standards, Korea issues a heat wave advisory when the maximum daily temperature is predicted to exceed $33^{\circ} \mathrm{C}$ for 2 consecutive days. In addition, a heat wave warning is issued when the daily maximum temperature is expected to exceed $35^{\circ} \mathrm{C}$ for 2 consecutive days [2].

The summer of 2018 was the hottest in Korea in at least 111 years, since domestic weather observations began. The highest daily temperature in Hongcheon on August 1, 2018 was $41.0^{\circ} \mathrm{C}$, breaking the record high for Korean regions. In addition, high temperature records were set in summer 2018 in many cities including Seoul. The national average length of the 2018 heat wave was 31.4 days and the average period of consecutive tropical nights was 17.7 days, both of which set annual records. Furthermore, the heat wave lasted for 37 days from July 11 to August 16, 2018-in Geumsan in the province of Chungcheongnam-do. Consequently, it is urgent to prepare measures to reduce the damage caused by heat waves in Korea, and this urgency coincides with a growing social interest in heat waves [3].

Any disease that affects thermoregulation can cause an increase in deaths due to heat waves. In particular, many studies have analyzed the relationship between heat waves and cardiovascular disease. When the body is exposed to heat during a heat wave, the cardiovascular system undergoes physiological changes, including dehydration and increased blood viscosity. The proper use of air conditioning during a heat wave can reduce heat exposure, thereby preventing abnormalities in thermoregulation and reducing the occurrence of physiological changes that can cause heat wave-related deaths [4]. Indeed, several studies have shown that proper control of the summer room temperature through air conditioning helps prevent deaths from heat waves [5-8]. However, air conditioning use has been found to differ based on socioeconomic factors, and these differences have resulted in disparities in deaths due to heat waves [9]. Insufficient research has been conducted on the relationship between air conditioner use and health effects other than death, such as physical and mental symptoms. In addition, there is still a lack of research on secondary damage, such as disruptions of daily life (absence in school or the workplace, lateness, cancellation of appointments, etc.) caused by the health effects of heat waves. To that end, this study aimed to investigate heat wave-related impacts by surveying participants regarding air conditioner use, their experience of physical or mental symptoms, and dis- ruptions in their daily lives during the 2018 heat wave in Korea, and to assess the relationship between air conditioner use and the effects of the heat wave on both health and daily life.

\section{METHODS}

\section{Study Population}

The participants in this study were 1000 adults aged 19 years and older from all regions of Korea. These participants were chosen from a panel of people who volunteered to participate in research conducted by the firm Korea Research (constituting about 430000 people as of August 2018). From this panel, 1000 adults were extracted in proportion to the full panel with regard to sex, age, place of residence, education, and occupation.

\section{Questionnaire Survey}

Surveys were used to collect data from the participants regarding their demographic and socioeconomic characteristics; health effects, such as physical and psychological symptoms, experienced during the 2018 heat wave; disruptions of their daily lives due to the heat wave; and air conditioning use during the heat wave. The authors of this study developed their own questionnaire to investigate the health effects of heat waves, and this questionnaire is included in Supplemental Material 1. The authors constructed the questionnaire over the course of internal discussions, and they verified the validity of the questionnaire by consulting with external experts in the relevant research fields. The survey was conducted by creating a Web page where participants could read the questionnaire and input their answers; the URL of the Web page was then sent to participants via text message or email. The survey was conducted on September 27 and 28, 2018.

With regard to demographic characteristics, the survey included sex, age, residence, and chronic disease status. Socioeconomic characteristics included occupation, type of house, number of members of the household, and monthly household income, with relative poverty defined as a monthly income lower than 50\% of the median income in Korea in 2018. The survey of health effects during the heat wave asked about the participant's experience of various physical or mental symptoms. First, the questions asked whether the participant experienced any symptoms of heat-related, skin, gastrointestinal, cardiovascular, renal and urinary, neurological, allergic, respiratory, mental, or sleep disorders during the heat wave. The 
survey also asked whether the participant had any symptoms of air-conditioningitis (for example, headache, dry mucous membranes, or myalgia) during the heat wave, whether he or she had visited medical institutions for these symptoms, and whether he or she had experienced any symptoms of food poisoning. In addition, the questionnaire asked about any disruptions of daily life caused by the heat wave, such as absence in school or the workplace, lateness, and cancellation of appointments. Regarding the use of air conditioning during the heat wave, the survey asked whether the main space where the respondent spent time outside the home was air-conditioned, whether there was an air conditioner in the home, the average daily duration of air conditioner use on weekdays and weekend days, the desired temperature set for the air conditioner, and whether the air conditioner was turned on while the inhabitants of the household were asleep. The survey also asked whether air conditioner use had been restricted due to electricity bills even when air conditioning was needed.

\section{Statistical Analysis}

This study used the chi-square test to analyze the relationship between whether the main space where the respondent spent time outside of the home was air-conditioned or whether there was an air conditioner in the home and health effects or disruptions of daily life during the heat. In addition, a multiple logistic regression model was used to control for potential confounding factors in the analysis of the relationship between air conditioner use and health effects during the heat wave. The average daily duration of air conditioning use in the home on weekdays and weekend days was dichotomized based on whether the number of hours was greater or less than the 75th percentile (10 hours and 15 hours for weekdays and weekend days, respectively). The temperature set for the air conditioner during the heat wave was also changed to a binary variable, based on whether the desired temperature was higher or lower than the 25 th percentile, $24^{\circ} \mathrm{C}$. This study compared the health effects of the heat wave on these groups based on their airconditioning usage time and the air conditioner temperature set. To adjust for potential confounding variables, the model included sex, age, area of residence, occupation, type of housing, number of members in the household, relative poverty status, obesity, and chronic disease status as covariates. All analyses used R version 3.5.1 (https://cran.r-project.org/bin/ windows/base/old/3.5.1/), and the statistical significance level $(\alpha)$ was set at 0.05 .

\section{Ethics Statement}

The research process of this study was approved by the Institutional Review Board of Dankook University Hospital, with consent to participate provided by all participants (DKUH2018-09-011).

\section{RESULTS}

Table 1 shows the demographic and socioeconomic characteristics of the 1000 participants. The proportion of males (50.3\%) was slightly higher than that of females, and Gyeonggi Province and Seoul (corresponding to the capital of Korea and its surrounding area) were the areas where the most participants resided, at $24.8 \%$ and $19.5 \%$, respectively. Most participants had occupations related to office work, management, or other professions (26.3\%) and lived in apartments (64.1\%). When comparing the monthly household incomes (accounting for the number of household members) of participants to the standard median income in Korea in 2018, $17.7 \%$ of participants fell below $50 \%$ of the standard median income, comparable to $17.4 \%$ of Koreans in 2017 , the most recent year with official data available on the relative poverty rate in Korea [10].

Table 2 shows the results of the survey questions on air conditioner use during the summer 2018 heat wave. Of the respon-

Table 1. Participants' characteristics ( $n=1000$ )

\begin{tabular}{lc}
\hline Characteristics & $\mathbf{n}(\%)$ \\
\hline Sex & $503(50.3)$ \\
Male & $497(49.7)$ \\
Female & \\
Age (y) & $177(17.7)$ \\
$19-30$ & $172(17.2)$ \\
$30-40$ & $201(20.1)$ \\
$40-50$ & $202(20.2)$ \\
$50-60$ & $248(24.8)$ \\
$\geq 60$ & $45.77 \pm 13.76$ \\
Mean \pm SD & \\
Area of residence & $195(19.5)$ \\
Seoul & $66(6.6)$ \\
Busan & $46(4.6)$ \\
Incheon & $60(6.0)$ \\
Daegu & $30(3.0)$ \\
Daejeon & $31(3.1)$ \\
Gwangju & $20(2.0)$ \\
Ulsan & $248(24.8)$ \\
Gyeonggi & (Continued to the next page) \\
\hline
\end{tabular}


Table 1. Continued from the previous page

\begin{tabular}{|c|c|}
\hline Characteristics & n (\%) \\
\hline Gyeongnam & $31(3.1)$ \\
\hline Gyeongbuk & $30(3.0)$ \\
\hline Jeonnam & $44(4.4)$ \\
\hline Jeonbuk & $34(3.4)$ \\
\hline Chungnam (including Sejong) & $30(3.0)$ \\
\hline Chungbuk & $55(5.5)$ \\
\hline Gangwon & $68(6.8)$ \\
\hline Jeju & $12(1.2)$ \\
\hline \multicolumn{2}{|l|}{ Occupation } \\
\hline Office work, management, or other profession & $263(26.3)$ \\
\hline Farming, fishing, or forestry & $18(1.8)$ \\
\hline Owner-operator & $117(11.7)$ \\
\hline Sales or service & $77(7.7)$ \\
\hline Production, technical service, or physical labor & $106(10.6)$ \\
\hline Housewife & $238(23.8)$ \\
\hline Student & $58(5.8)$ \\
\hline Unemployed, retired, or other occupations & $123(12.3)$ \\
\hline \multicolumn{2}{|l|}{ Type of housing } \\
\hline Apartment & $641(64.1)$ \\
\hline Detached house & $164(16.4)$ \\
\hline Multiplex house & $174(17.4)$ \\
\hline Studio apartment & $9(0.9)$ \\
\hline Other & $12(1.2)$ \\
\hline \multicolumn{2}{|l|}{ No. of household members (n) } \\
\hline 1 & $75(7.5)$ \\
\hline 2 & $214(21.4)$ \\
\hline 3 & $264(26.4)$ \\
\hline 4 & $332(33.2)$ \\
\hline$\geq 5$ & $115(11.5)$ \\
\hline Mean \pm SD & $3.23 \pm 1.19$ \\
\hline \multicolumn{2}{|l|}{ Monthly household income (10 Korean won) } \\
\hline Income $<200$ & $129(12.9)$ \\
\hline $200 \leq$ Income $<300$ & $178(17.8)$ \\
\hline $300 \leq$ Income $<400$ & $228(22.8)$ \\
\hline $400 \leq$ Income $<500$ & $198(19.8)$ \\
\hline Income $\geq 500$ & $267(26.7)$ \\
\hline \multicolumn{2}{|l|}{ Relative poverty } \\
\hline No & $823(82.3)$ \\
\hline Yes & $177(17.7)$ \\
\hline \multicolumn{2}{|l|}{ Obesity (BMI $\geq 25.0$ kg/m²) } \\
\hline No & $668(66.8)$ \\
\hline Yes & $332(33.2)$ \\
\hline \multicolumn{2}{|l|}{ Presence of a chronic disease } \\
\hline No & $763(76.3)$ \\
\hline Yes & $237(23.7)$ \\
\hline
\end{tabular}

SD, standard deviation; BMI, body mass index.
Table 2. Characteristics of participants regarding air conditioning use during the 2018 heat wave $(n=1000)$

\begin{tabular}{lc}
\hline Characteristics & $\begin{array}{c}\text { n (\%) or } \\
\text { mean } \pm \text { SD }\end{array}$ \\
\hline $\begin{array}{l}\text { Air conditioning in the main space where the respondent } \\
\text { spent time outside the home }\end{array}$ & $62(6.2)$ \\
$\quad$ Not used & $938(93.8)$ \\
Used & \\
Had a home air conditioner & $100(10.0)$ \\
No & $900(90.0)$ \\
Yes & $7.74 \pm 5.54$ \\
Average use time of domestic air conditioner on weekdays (hr) & $10.58 \pm 6.24$ \\
Average use time of domestic air conditioner on weekend & \\
days and holidays (hr) & $25.24 \pm 2.33$ \\
Average temperature set for the air conditioner (') & \\
Air conditioning use during sleep ${ }^{1}$ & $155(17.2)$ \\
Did not use & $300(33.3)$ \\
Used for 1-2 hours & $240(26.7)$ \\
Used but repeatedly turned on and off & $205(22.8)$ \\
Used continuously overnight & \\
Limited air conditioner use due to electricity bill' & $208(23.1)$ \\
No & $692(76.9)$ \\
Yes &
\end{tabular}

${ }^{1}$ In participants who had a home air conditioner.

dents, 93.8\% said that air conditioning was turned on during the heat wave at the main spaces where they spent time outside the home, such as work and school, and $90.0 \%$ of respondents reported having an air conditioner at home during that time. The average daily duration of air conditioning use at home on weekdays was 7.74 hours, which was approximately 3 hours shorter than the average daily usage on weekend days. Furthermore, $82.8 \%$ of respondents with home air conditioners used the air conditioning while the household inhabitants slept, and $76.9 \%$ of respondents with home air conditioners reported that they had restricted air conditioner use or did not use air conditioning at all due to electricity bills.

Table 3 shows the total frequencies of health effects and disruptions of daily life during the heat wave. Additionally, those frequencies were divided by whether an air conditioner was operated in the main space where the respondent spent time outside the home and whether there was an air conditioner in the home. Of the 1000 participants, 50.7\% reported experiencing physical or mental symptoms, and $37.6 \%, 36.1 \%$, and $34.4 \%$ reported having symptoms of sleep disorders, gastrointestinal diseases, and skin diseases, respectively. Furthermore, $33.3 \%$ of the participants had experienced symptoms of 
air-conditioningitis, such as headache, dry mucous membranes, and myalgia; $16.5 \%$ of participants had visited medical institutions due to symptoms of air-conditioningitis, and $15.4 \%$ had experienced symptoms of food poisoning. Of the participants, $51.3 \%$ had canceled appointments due to the heat wave, a proportion higher than the proportions of participants who had been absent from work or school (4.3\%) and who had been late (12.5\%) as a result of the heat wave. Statistically significant differences were found regarding whether air conditioning was used in the main space where the re- spondent spent time outside the home and whether there was an air conditioner at home. Participants for which air conditioning was not used in the main space where they spent time outside the house experienced symptoms of heat-related, cardiovascular, neurological disease, and air-conditioningitis at proportions of $33.9 \%, 8.1 \%, 43.5 \%$, and $19.4 \%$, respectively, while those with air conditioning used in the main space where they spent time outside the home experienced these symptoms at proportions of $21.0 \%, 1.9 \%, 26.8 \%$, and $34.2 \%$, respectively $(p=0.027,0.007,0.007$, and 0.023 , respec-

Table 3. Frequencies of health problems induced by the 2018 heat wave

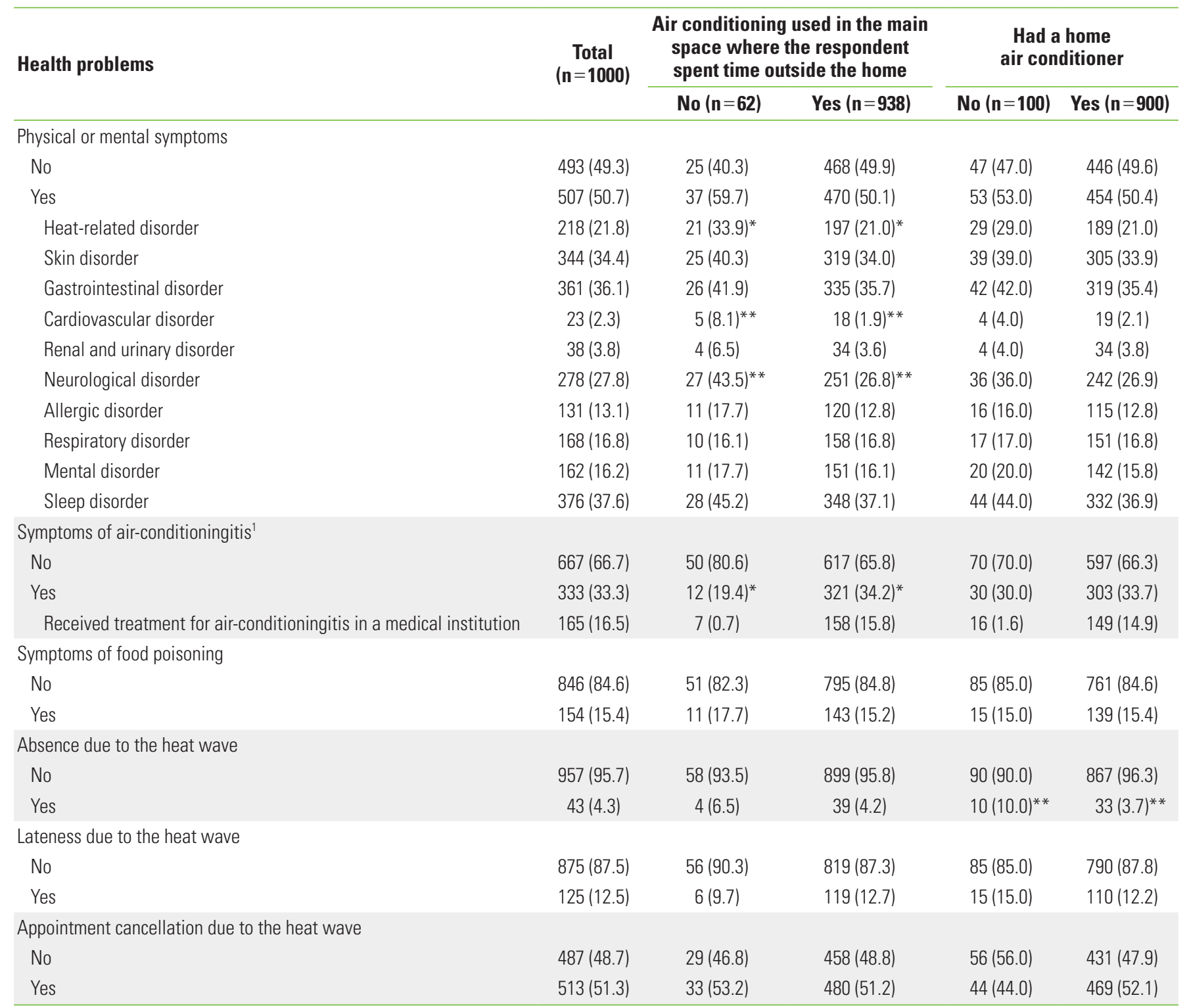

Values are presented as number (\%).

${ }^{1}$ Symptoms of air-conditioningitis include headache, myalgia, and dry mucous membranes of the eye, nose, mouth, or throat during or after using an air conditioner.

${ }^{*} p<0.05,{ }^{* *} p<0.01$. 
tively). Additionally, $10.0 \%$ of participants without a home air conditioner reported having been absent due to the heat wave, in contrast to only $3.7 \%$ of participants with a home air conditioner $(p=0.007)$.

Table 4 shows the results of the multiple logistic regression analysis with adjustment for covariates to determine the relationships among air conditioner use during the heat wave, restriction of air conditioner use due to electric bills, and health effects or disruptions of daily life. Participants for whom air conditioning was not used outside of the home during the heat wave were more likely to report symptoms related to cardiovascular disorders (odds ratio [OR], 8.32; 95\% confidence interval $[\mathrm{Cl}], 1.86$ to 37.23 ) and neurological disorders (OR, $2.07 ; 95 \% \mathrm{Cl}, 1.17$ to 3.66 ), while participants with no air conditioner at home more frequently reported symptoms related to neurological disorders $(\mathrm{OR}, 1.65 ; 95 \% \mathrm{Cl}, 1.03$ to 2.63$)$, as well as a higher likelihood of absence (OR, 3.49; $95 \% \mathrm{Cl}, 1.48$ to 8.22). Respondents, who answered that the air conditioner usage was restricted due to electricity bills, were more likely to report physical or mental symptoms in general (OR, 1.78; 95\% $\mathrm{Cl}, 1.27$ to 2.48), symptoms related to skin disorders (OR, 1.92; $95 \% \mathrm{Cl}, 1.32$ to 2.80$)$, gastrointestinal disorders (OR, 1.63; $95 \%$ $\mathrm{Cl}, 1.14$ to 2.34$)$, renal and urinary disorders $(\mathrm{OR}, 5.01 ; 95 \% \mathrm{Cl}$, 1.10 to 22.81 ), neurological disorders ( $\mathrm{OR}, 1.55 ; 95 \% \mathrm{Cl}, 1.04$ to 2.30), and sleep disorders (OR, 1.58; $95 \% \mathrm{Cl}, 1.11$ to 2.26$)$ and were more likely to have been late $(\mathrm{OR}, 1.81 ; 95 \% \mathrm{Cl}, 1.04$ to $3.14)$ and to have canceled appointments $(\mathrm{OR}, 1.86 ; 95 \% \mathrm{Cl}$, 1.33 to 2.61 ) than participants who did not restrict usage due to bills during the heat wave. The results of the logistic regression analysis without correction for covariates are shown in Supplemental Material 2, and no significant difference in the direction and statistical significance was found between these results and those detailed in Table 4. The results of the subgroups by chronic disease status are listed in Supplemental Materials 3 and 4, and participants with chronic diseases tended to have stronger relationships as mentioned above than participants without chronic diseases. The results of the subgroups by age ( 60 years and older vs. under 60 years old) are

Table 4. ORs for deleterious health effects and air conditioning infrastructure in participants using a multiple logistic regression model

\begin{tabular}{|c|c|c|c|c|c|c|}
\hline Health problems & \multicolumn{2}{|c|}{$\begin{array}{l}\text { No air conditioning used } \\
\text { in the main space where the } \\
\text { respondent spent time } \\
\text { outside the home }\end{array}$} & \multicolumn{2}{|c|}{$\begin{array}{l}\text { No air conditioner } \\
\text { in the home }\end{array}$} & \multicolumn{2}{|c|}{$\begin{array}{l}\text { Restricted air conditioner use } \\
\text { due to electricity bills }\end{array}$} \\
\hline Physical or mental symptoms & 0.29 & $1.63(0.93,2.86)$ & 0.22 & $1.09(0.70,1.68)$ & 0.17 & $1.78(1.27,2.48)$ \\
\hline Heat-related disorder & 0.31 & $1.73(0.95,3.15)$ & 0.26 & $1.33(0.80,2.20)$ & 0.22 & $1.47(0.95,2.28)$ \\
\hline Gastrointestinal disorder & 0.29 & $1.32(0.75,2.32)$ & 0.23 & $1.36(0.87,2.13)$ & 0.18 & $1.63(1.14,2.34)$ \\
\hline Cardiovascular disorder & 0.76 & $8.32(1.86,37.23)$ & 0.74 & $1.86(0.44,7.92)$ & 0.90 & $1.49(0.26,8.61)$ \\
\hline Renal and urinary disorder & 0.66 & $2.14(0.59,7.83)$ & 0.60 & $1.78(0.54,5.80)$ & 0.77 & $5.01(1.10,22.81)$ \\
\hline Neurological disorder & 0.29 & $2.07(1.17,3.66)$ & 0.24 & $1.65(1.03,2.63)$ & 0.20 & $1.55(1.04,2.30)$ \\
\hline Allergic disorder & 0.39 & $1.41(0.65,3.03)$ & 0.31 & $1.25(0.68,2.32)$ & 0.26 & $1.15(0.69,1.93)$ \\
\hline Symptoms of air-conditioningitis & 0.35 & $0.60(0.30,1.20)$ & 0.24 & $0.88(0.55,1.42)$ & 0.18 & $1.09(0.76,1.56)$ \\
\hline Received treatment for air-conditioningitis & 0.44 & $1.01(0.43,2.39)$ & 0.31 & $1.15(0.63,2.10)$ & 0.24 & $1.36(0.85,2.18)$ \\
\hline Symptoms of food poisoning & 0.37 & $1.48(0.72,3.07)$ & 0.31 & $1.11(0.60,2.04)$ & 0.25 & $1.62(0.99,2.66)$ \\
\hline Absence due to the heat wave & 0.61 & $1.35(0.41,4.42)$ & 0.44 & $3.49(1.48,8.22)$ & 0.48 & $1.29(0.51,3.29)$ \\
\hline Lateness due to the heat wave & 0.48 & $0.84(0.33,2.15)$ & 0.33 & $1.52(0.80,2.90)$ & 0.28 & $1.81(1.04,3.14)$ \\
\hline Appointment cancellation due to the heat wave & 0.29 & $1.21(0.69,2.12)$ & 0.23 & $0.79(0.50,1.23)$ & 0.17 & $1.86(1.33,2.61)$ \\
\hline
\end{tabular}

Reference group: air conditioning used in the main space where the respondent spent time outside the home, had an air conditioner at home, and did not restrict air conditioner use due to electricity bills.

Covariates: sex, age, residential area, job, type of housing, number of household members, relative poverty (defined as a monthly household income less than $50 \%$ of the standard median income), obesity (body mass index $\geq 25 \mathrm{~kg} / \mathrm{m}^{2}$ ), and presence of a chronic disease.

$\mathrm{OR}$, odds ratio; SE, standard error; Cl, confidence interval. 
shown in Supplemental Materials 5 and 6. No consistent trends by age were observed in the data.

Table 5 shows the results of multiple logistic regression analysis for the relationships of air conditioner use duration, the temperature set for the air conditioner, and whether the air conditioner was used while inhabitants slept with health effects or disruptions of daily life. Participants who used an air conditioner for more than $10 \mathrm{hr} / \mathrm{d}$ on weekdays during the heat wave were more likely to report symptoms of air-conditioningitis (OR, 1.53; 95\% Cl, 1.12 to 2.09), visits to medical institutions due to air-conditioning $(\mathrm{OR}, 1.77 ; 95 \% \mathrm{Cl}, 1.21$ to 2.59), and canceled appointments $(\mathrm{OR}, 1.36 ; 95 \% \mathrm{Cl}, 1.00$ to 1.85). Additionally, those who used an air conditioner for more than $15 \mathrm{hr} / \mathrm{d}$ on weekend days and holidays during the heat wave were more likely to report visits to medical institutions due to air-conditioningitis (OR, 1.55; $95 \% \mathrm{Cl}, 1.05$ to 2.28). Participants who set the temperature to $24^{\circ} \mathrm{C}$ or lower during the heat wave were more likely to report symptoms of heatrelated disorders (OR, 1.48; $95 \% \mathrm{Cl}, 1.06$ to 2.05 ), neurological disorders (OR, 1.56; $95 \% \mathrm{Cl}, 1.15$ to 2.11 ), allergic disorders (OR,
1.55; $95 \% \mathrm{Cl}, 1.04$ to 2.30$)$, and mental disorders (OR, 1.61; $95 \% \mathrm{Cl}, 1.12$ to 2.32 ). Additionally, those who reported using an air conditioner while the inhabitants of the household slept were more likely to report symptoms of respiratory disorders (OR, 1.90; 95\% Cl, 1.20 to 2.99), air-conditioningitis ( $\mathrm{OR}$, $1.61 ; 95 \% \mathrm{Cl}, 1.15$ to 2.27 ), visits to medical institutions (OR, $1.63 ; 95 \% \mathrm{Cl}, 1.03$ to 2.59 ), and canceled appointments (OR, $1.44 ; 95 \% \mathrm{Cl}, 1.06$ to 1.96$)$ than participants who did not use an air conditioner during sleep. The results of the logistic regression analysis without correction for covariates are listed in Supplemental Material 7, and no significant difference was found in the direction and statistical significance between these results and those detailed in Table 5. The results of the subgroups by chronic disease status are listed in Supplemental Materials 8 and 9, and participants with chronic diseases tended to have stronger relationships as mentioned above than participants without chronic diseases. The results of the subgroups by age (60 years and older vs. under 60 years old) are shown in Supplemental Materials 10 and 11. No consistent trends by age were observed in the data.

Table 5. ORs for deleterious health effects according to air conditioner use in participants using a multiple logistic regression model

\begin{tabular}{|c|c|c|c|c|c|c|c|c|}
\hline \multirow{2}{*}{ Health problems } & \multicolumn{2}{|r|}{$\begin{array}{l}\text { Weekdays, } \\
\geq 10 \mathrm{hr} / \mathrm{d}\end{array}$} & \multicolumn{2}{|c|}{$\begin{array}{l}\text { Weekend and holiday, } \\
\quad \geq 15 \mathrm{hr} / \mathrm{d}\end{array}$} & \multicolumn{2}{|c|}{$\begin{array}{l}\text { Setting temperature, } \\
<24^{\circ} \mathrm{C}\end{array}$} & \multicolumn{2}{|c|}{ During sleep } \\
\hline & SE & OR (95\% Cl) & SE & OR $(95 \% \mathrm{Cl})$ & SE & OR $(95 \% \mathrm{CI})$ & SE & OR $(95 \% \mathrm{CI})$ \\
\hline Physical or mental symptoms & 0.16 & $1.08(0.79,1.46)$ & 0.16 & $1.21(0.88,1.65)$ & 0.14 & $1.08(0.82,1.42)$ & 0.15 & $1.33(0.98,1.80)$ \\
\hline Heat-related disorder & 0.19 & $1.06(0.73,1.55)$ & 0.20 & $1.10(0.75,1.62)$ & 0.17 & $1.48(1.06,2.05)$ & 0.19 & $1.19(0.82,1.74)$ \\
\hline Skin disorder & 0.16 & $1.03(0.74,1.41)$ & 0.17 & $1.05(0.76,1.46)$ & 0.15 & $1.31(0.98,1.74)$ & 0.17 & $1.19(0.86,1.65)$ \\
\hline Gastrointestinal disorder & 0.16 & $0.94(0.68,1.29)$ & 0.16 & $1.09(0.79,1.50)$ & 0.14 & $1.18(0.89,1.57)$ & 0.16 & $1.14(0.83,1.57)$ \\
\hline Cardiovascular disorder & 0.56 & $1.00(0.33,3.00)$ & 0.57 & $1.58(0.51,4.86)$ & 0.51 & $1.27(0.47,3.45)$ & 0.58 & $1.23(0.39,3.84)$ \\
\hline Renal and urinary disorder & 0.48 & $0.41(0.16,1.05)$ & 0.47 & $0.58(0.23,1.46)$ & 0.37 & $1.55(0.75,3.23)$ & 0.46 & $1.25(0.50,3.09)$ \\
\hline Neurological disorder & 0.17 & $0.89(0.64,1.26)$ & 0.18 & $0.94(0.66,1.34)$ & 0.16 & $1.56(1.15,2.11)$ & 0.17 & $0.83(0.60,1.16)$ \\
\hline Allergic disorder & 0.23 & $0.94(0.59,1.48)$ & 0.24 & $0.88(0.55,1.43)$ & 0.20 & $1.55(1.04,2.30)$ & 0.23 & $0.90(0.57,1.40)$ \\
\hline Respiratory disorder & 0.20 & $1.33(0.89,1.98)$ & 0.21 & $1.27(0.85,1.91)$ & 0.18 & $1.22(0.85,1.74)$ & 0.23 & $1.90(1.20,2.99)$ \\
\hline Mental disorder & 0.21 & $0.86(0.57,1.30)$ & 0.22 & $0.98(0.64,1.49)$ & 0.19 & $1.61(1.12,2.32)$ & 0.21 & $0.98(0.65,1.48)$ \\
\hline Sleep disorder & 0.16 & $1.06(0.77,1.44)$ & 0.16 & $1.09(0.80,1.50)$ & 0.14 & $1.20(0.91,1.59)$ & 0.16 & $1.19(0.87,1.63)$ \\
\hline Symptoms of air-conditioningitis & 0.16 & $1.53(1.12,2.09)$ & 0.17 & $1.30(0.94,1.80)$ & 0.15 & $1.14(0.85,1.53)$ & 0.17 & $1.61(1.15,2.27)$ \\
\hline Received treatment for air-conditioningitis & 0.19 & $1.77(1.21,2.59)$ & 0.20 & $1.55(1.05,2.28)$ & 0.19 & $1.39(0.96,2.00)$ & 0.24 & $1.63(1.03,2.59)$ \\
\hline Symptoms of food poisoning & 0.21 & $1.12(0.74,1.70)$ & 0.22 & $0.94(0.61,1.46)$ & 0.19 & $1.16(0.80,1.68)$ & 0.22 & $1.14(0.74,1.76)$ \\
\hline Absence due to the heat wave & 0.41 & $0.91(0.40,2.04)$ & 0.41 & $1.20(0.54,2.65)$ & 0.34 & $1.32(0.68,2.57)$ & 0.36 & $0.57(0.28,1.14)$ \\
\hline Lateness due to the heat wave & 0.25 & $0.88(0.54,1.44)$ & 0.25 & $1.08(0.66,1.77)$ & 0.22 & $0.80(0.52,1.22)$ & 0.24 & $1.05(0.65,1.70)$ \\
\hline Appointment cancellation due to the heat wave & 0.16 & $1.36(1.00,1.85)$ & 0.16 & $1.22(0.89,1.68)$ & 0.14 & $1.07(0.81,1.41)$ & 0.16 & $1.44(1.06,1.96)$ \\
\hline
\end{tabular}

Reference group: used air conditioner for fewer than $10 \mathrm{hr} / \mathrm{d}$ on weekdays, used air conditioner for fewer than $15 \mathrm{hr} / \mathrm{d}$ on weekend days and holidays, used air conditioner set higher than $24^{\circ} \mathrm{C}$, and did not use air conditioner during sleep.

Covariates: sex, age, residential area, job, type of housing, number of household members, relative poverty (defined as a monthly household income less than $50 \%$ of the standard median income), obesity (body mass index $\geq 25 \mathrm{~kg} / \mathrm{m}^{2}$ ), and presence of a chronic disease.

$\mathrm{OR}$, odds ratio; $\mathrm{SE}$, standard error; $\mathrm{Cl}$, confidence interval. 


\section{DISCUSSION}

The purpose of this study was to identify the types and frequencies of health effects that occurred during the heat wave in Korea in 2018 and to examine the relationship between air conditioner use and heat wave-related health effects. During the 2018 heat wave, $50.7 \%$ of participants experienced physical or mental symptoms resulting from the heat wave, and a statistically significant relationship was observed between air conditioner use and health effects or disruptions of daily life resulting from the heat wave. Participants for whom no air conditioning was used in the main space where they spent time outside the home were more likely to experience physical symptoms such as heat-related disorders, cardiovascular disorders, and neurological disorders than those for whom air conditioning was used, but they were less likely to experience symptoms of air-conditioningitis. Participants without air conditioning at home were more likely to be absent from work or school due to the heat wave than those with air conditioning at home. Additionally, the results of multiple logistic regression analysis after correcting for covariates showed that participants were more likely to experience physical or mental symptoms or disruptions of daily life when an air conditioner was not operated in the main space where they spent time outside the home, when there was no air conditioner in the home, and when they restricted air conditioner use due to electric bills despite the need for it. However, the results for the relationship between air conditioner usage duration, the temperature set for the air conditioner, the use of air conditioning during sleep, and health effects due to the heat wave indicated that the excessive use of air conditioning also had adverse effects on health. The subgroup analysis showed that this association was greater for participants with chronic diseases than for participants without such diseases.

Previous studies have reported similar results regarding the relationship between air conditioner use and health effects. A case-control study conducted in Chicago, United States, in 1995 found that the use of air conditioning at home reduced the risk of heat wave-related deaths by $70 \%$ compared to homes without air conditioning [6]. A cohort study conducted in the United States from 1980 to 1985 found that the use of central air conditioning at home reduced the risk of heat wave-related deaths by $42 \%$ compared to homes without any air conditioning [7]. Another cohort study conducted in Portugal in 2003 found that patients who were hospitalized in wards with air conditioning in the 7 days prior to the heat wave had a $40 \%$ lower mortality risk than those who were hospitalized in wards without air conditioning [8]. Therefore, the positive effects of air conditioner use on health demonstrated in the present study are consistent with the results of previous studies. Furthermore, while previous studies examined the health effects of heat waves through their impact on deaths, it is notable that this study produced similar results even though it analyzed multiple health outcomes other than death. A study conducted in the United States from 1986 to 1993 showed that the prevalence of central air conditioning among African-American families was less than half of that among Caucasian families, and the rate of heat-related mortality was more than double in African-Americans compared to Caucasians [9]. These previous findings are consistent with the result of the present study that negative effects on health were observed when the infrastructure did not support air conditioning. Several studies have clearly demonstrated that heat waves increase the number of deaths [5-7,11-15] and cause more damage to vulnerable groups [16-18], such as low-income elderly households, who cannot support the use of household air conditioners during heat waves without assistance in the form of energy subsidies. Thus, adequate support is necessary to effectively respond to vulnerable groups during a heat wave $[17,18]$. The negative health impact of restricting air conditioner use due to electric bills demonstrated in the present study aligns with the results of those previous studies.

This study has several strengths. First, it timely surveyed and analyzed the health effects of the $\mathbf{2 0 1 8}$ heat wave in Korea, as social interest is rising and demand for research into heat waves is growing due to global warming. Additionally, while most previous studies on the health effects of heat waves estimated the magnitude of those effects using excess mortality, the number of heat-related illnesses, and the number of heatrelated deaths, this study analyzed a wider range of health effects, using various physical and mental symptoms as major health outcomes. Because the questionnaire also asked about secondary outcomes caused by heat waves, such as absence, lateness, and cancellation of appointments, it was therefore possible to analyze the effects of heat waves on daily life, which cannot be judged solely by medical treatments, symptoms, and disease occurrence. In addition, this study analyzed air conditioner usage during the heat wave and the health effects of the heat wave from various viewpoints, such as infra- 
structural support for air conditioner use and the behavior of those who used air conditioners.

However, this study also has several limitations. First, because the study was conducted after the end of the heat wave, recall bias may have occurred. For example, participants who did not have air conditioning in their home or in the main space where they spent time outside the home during the heat wave may have remembered more about the effects of the heat wave, such as physical or mental symptoms and absences from work or school, than those who did. In order to minimize these biases, this study was designed and the questionnaire survey prepared as quickly as possible after the heat wave. We conducted the survey on September 27 and 28, 2018, which was approximately 1 month after the end of the heat wave in Korea (August 22, 2018). However, to facilitate carrying out the survey as soon as possible, the online survey was conducted with 1000 samples drawn from a panel registered with a research company. As a result, a high proportion of the study participants belonged to specific groups with regard to occupation, such as office workers and housewives. Thus, it may be unreasonable to generalize the results of this study to all Koreans, so any future research should be conducted using more representative groups. In addition, due to the limited time available to develop the questionnaire and to conduct the survey, pilot study and preliminary analysis were not sufficiently performed to ensure the objective validity of the questionnaire developed by the authors of this study. In future studies, if this process is faithfully carried out, the questionnaire used may have higher demonstrated validity.

This study also did not take participants' lifestyle factors, such as smoking and drinking, into account, and thus could not correct for the health effects of different lifestyles. Additionally, since residential area was examined only with regard to administrative areas within a province, it was not possible to clearly determine whether participants resided in urban areas, and thus any health effects from the heat wave due to the urban heat island effect could not be examined. In addition, although relative poverty was analyzed as a covariate, it is possible that the socioeconomic variables related to the health effects of heat waves were not sufficiently corrected for. Future research should be conducted to obtain results that account for these potential confounding factors.

Furthermore, this study did not clearly define chronic diseases when surveying participants regarding chronic disease status, and it did not investigate whether the participants had those chronic diseases before the heat wave. Therefore, it was difficult to distinguish whether the physical or mental symptoms that occurred during the heat wave were caused by a pre-existing chronic disease or by the heat wave. Additionally, this study cannot rule out the possibility that the temporal relationship between the ownership of air conditioners and air conditioner use, which are the main causative variables, and the presence or absence of chronic diseases, which are covariates, may be reversed. The health outcomes associated with air-conditioningitis have a relatively clear relationship with the operation of air conditioners, but for other health outcomes, these causal issues cannot be ruled out. Moreover, since this study is a cross-sectional study, it has a limited capacity to correct for the possibility of reverse causality, so the interpretation of the ORs calculated through the multiple logistic regression model in this study is limited. In order to overcome these limitations, it is necessary to establish a chronic disease cohort to investigate the health effects of heat waves in future studies.

Additionally, this study used a questionnaire to investigate the presence of physical or mental symptoms during the heat wave, so it may be less objective than if it had used hospital records. However, the health effects of heat waves also impact individuals who do not visit a hospital. Thus, in this study, the presence of symptoms was investigated through a questionnaire to account for those individuals in the analysis. In future studies, in order to increase objectivity, it may be possible to obtain the hospital records by obtaining consent for the use of secondary health data, such as National Health Insurance database, from survey participants and to link them with the survey results.

It also was not possible to quantitatively assess the secondary damage of heat waves, such as absence, lateness, and appointment cancellation, during the heat wave period. The survey asked about the number of times the participant experienced each item, but those who had such experiences answered that they had experienced most of the items only once. Future studies could conduct a quantitative assessment of the secondary damage of heat waves by surveying more participants or by using a survey that enables a more detailed evaluation than was possible using the items examined in this study.

Despite these limitations, this study is meaningful because it examined the health effects of a recent heat wave and the relationship between air conditioner use and heat-related health effects. This study investigated and analyzed a broad range of symptomatic health effects due to heat waves, and 
the data obtained may serve as a reference for the design of subsequent studies on the deleterious health effects of heat waves. In addition, this study demonstrated that during a heat wave, not only can a lack of air conditioning in the home or main space outside the home adversely affect health and daily life, but also that the excessive use of air conditioning can increase the risk of air-conditioningitis. These findings can be used as an academic basis for intervention methods and policy-setting to minimize the damage caused by heat waves in the future.

\section{SUPPLEMENTAL MATERIALS}

Supplemental materials are available at https://doi.org/10. 3961/jpmph.19.171.

\section{CONFLICT OF INTEREST}

The authors have no conflicts of interest associated with the material presented in this paper.

\section{FUNDING}

This research was funded by the Korea Centers for Disease Control and Prevention R\&D (2018-P1404-00 \#).

\section{ACKNOWLEDGEMENTS}

None.

\section{AUTHOR CONTRIBUTIONS}

Conceptualization: YHL, SB, SSH, JHK, KNK, YHL, HJK. Data curation: YHL, SB, HJK. Formal analysis: YHL, SB, HJK. Funding acquisition: HJK. Methodology: YHL, SB, SSH, JHK, KNK, YHL, MK, SJ, HJK. Project administration: SB, SSH, JHK, KNK, YHL, HJK. Writing - original draft: YHL. Writing - review \& editing: YHL, SB, SSH, JHK, KNK, YHL, MK, SJ, HJK.

\section{ORCID}

Yong-Han Lee https://orcid.org/0000-0002-4130-8445

Sanghyuk Bae https://orcid.org/0000-0002-4995-6543

Seung-sik Hwang https://orcid.org/0000-0002-1558-7831

Jong-Hun Kim https://orcid.org/0000-0002-4974-5180
Kyoung-Nam Kim https://orcid.org/0000-0002-8715-9238

Youn-Hee Lim https://orcid.org/0000-0002-1290-5814

Miji Kim https://orcid.org/0000-0002-8646-832X

Sohwa Jung https://orcid.org/0000-0001-9616-3792

Ho-Jang Kwon https://orcid.org/0000-0002-9774-0480

\section{REFERENCES}

1. National Weather Service. A weather hazard of summer; 2019 [cited 2019 Jun 1]. Available from: https://www.weather.gov/ btv/heat_awareness.

2. Korean Meteorological Administration. Criteria for advisory/ warning information [cited 2019 Jun 1]. Available from: http:// www.kma.go.kr/eng/weather/forecast/standard_warning_ info.jsp.

3. Interagency of Korean Government. 2018 Abnormal climate report; 2019 [cited 2020 Jan 17]. Available from: http://www. climate.go.kr/home/cc_data/2019/2018_abnormal_climate_ report.pdf (Korean).

4. Kovats RS, Hajat $S$. Heat stress and public health: a critical review. Annu Rev Public Health 2008;29:41-55.

5. Ito K, Lane K, Olson C. Equitable access to air conditioning: a city health department's perspective on preventing heat-related deaths. Epidemiology 2018;29(6):749-752.

6. Semenza JC, Rubin CH, Falter KH, Selanikio JD, Flanders WD, Howe $\mathrm{HL}$, et al. Heat-related deaths during the July 1995 heat wave in Chicago. N Engl J Med 1996;335(2):84-90.

7. Rogot E, Sorlie PD, Backlund E. Air-conditioning and mortality in hot weather. Am J Epidemiol 1992;136(1):106-116.

8. Nunes B, Paixão E, Dias CM, Nogueira P, Marinho Falcão J. Air conditioning and intrahospital mortality during the 2003 heatwave in Portugal: evidence of a protective effect. Occup Environ Med 2011;68(3):218-223.

9. O'Neill MS, Zanobetti A, Schwartz J. Disparities by race in heat-related mortality in four US cities: the role of air conditioning prevalence. J Urban Health 2005;82(2):191-197.

10. Korean Statistical Information Service. The index of income distribution; 2019 [cited 2020 Jan 17] Available from: http:// kosis.kr/statHtml/statHtml.do?orgld=101\&tblld=DT_1HDLF 05\&checkFlag $=\mathrm{N}$ (Korean).

11. Della-Marta PM, Luterbacher J, von Weissenfluh H, Xoplaki E, Brunet $M$, Wanner $H$. Summer heat waves over western Europe 1880-2003, their relationship to large-scale forcings and predictability. Clim Dyn 2007;29(2-3):251-275.

12. Porfiriev B. Evaluation of human losses from disasters: the 
case of the 2010 heat waves and forest fires in Russia. Int J Disaster Risk Reduct 2014;7:91-99.

13. Kysely J, Kim J. Mortality during heat waves in South Korea, 1991 to 2005: how exceptional was the 1994 heat wave? Clim Res 2009;38(2):105-116.

14. Korea Centers for Disease Control and Prevention. Annual report on the notified patients with heat-related illness in Korea [cited 2020 Jan 17]. Available from: http://www.nih.go.kr/ contents.es?mid $=$ a20304010700 (Korean).

15. Le Tertre A, Lefranc A, Eilstein D, Declercq C, Medina S, Blanchard M, et al. Impact of the 2003 heatwave on all-cause mortality in 9 French cities. Epidemiology 2006;17(1):75-79.
16. Wang XY, Barnett A, Guo YM, Yu WW, Shen XM, Tong SL. Increased risk of emergency hospital admissions for children with renal diseases during heatwaves in Brisbane, Australia. World J Pediatr 2014;10(4):330-335.

17. Farbotko C, Waitt G. Residential air-conditioning and climate change: voices of the vulnerable. Health Promot J Austr 2011; 22(4):13-15.

18. Richard L, Kosatsky T, Renouf A. Correlates of hot day air-conditioning use among middle-aged and older adults with chronic heart and lung diseases: the role of health beliefs and cues to action. Health Educ Res 2011;26(1):77-88. 